\title{
REFLEXÕES RETROSPECTIVAS E PROSPECTIVAS SOBRE A GOVERNANÇA TERRITORIAL PARA O DESENVOLVIMENTO RURAL NO BRASIL
}

\author{
Marc Piraux ${ }^{1}$ \\ Márcio Caniello ${ }^{2}$
}

\begin{abstract}
RESUMO
Entre 2003 e 2016, o governo federal brasileiro implementou o Programa Nacional de Desenvolvimento Sustentável dos Territórios Rurais (PRONAT), cuja "governança" se processava em colegiados participativos paritários formados pelos atores sociais, suas organizações e representantes governamentais. Este trabalho tem como objetivos: (i) avaliar os avanços e entraves da governança territorial do PRONAT, por meio da análise do "ciclo de gestão social", cerne do processo decisório participativo; e (ii) apresentar propostas para um ajuste de rumos da governança territorial no país, em favor de sua retomada por um eventual governo federal progressista ou em estados da Federação que adotem essa perspectiva. Para tanto, os autores expõem e interpretam o Índice de Gestão Social (IGS), inferido pelo cálculo de nove indicadores agrupados em três dimensões, a partir de tabulação estatística de 785 questionários aplicados a membros ativos de colegiados territoriais de 33 Territórios da Cidadania, cujos escores são confrontados com dados e reflexões produzidas em duas pesquisas nacionais sobre a temática, realizadas entre 2010 e 2017.
\end{abstract}

Palavras-chave: Governança Territorial, Desenvolvimento Rural, Gestão Social, Brasil.

\section{RETROSPECTIVE AND PROSPECTIVE REFLECTIONS ON TERRITORIAL GOVERNANCE FOR RURAL DEVELOPMENT IN BRAZIL}

\begin{abstract}
Between 2003 and 2016, the Brazilian federal government implemented the National Program for the Sustainable Development of Rural Territories (PRONAT), whose "governance" took place within participatory institutional arrangements formed by social actors groups, their organizations and government representatives through equal parity in representation. This work aims to: (i) assess the progress and constraints of territorial governance in this program in Brazil, through analysis of the "social management cycle", the participatory decision-making process and (ii) to present proposals for an adjustment of territorial governance in the country, in favor of its recovery by an eventual progressive federal government or in States of the Federation that adopt this perspective. To this end, the authors expose and interpret the Social Management Index (IGS), inferred by calculating nine indicators grouped in three dimensions, based on the statistical tabulation of 785 questionnaires applied to active members of territorial colleges bodies in 33 Citizenship Territories, whose scores are compared with data and reflections produced in two national surveys, carried out between 2010 and 2017.
\end{abstract}

Keywords: Territorial Governance, Rural Development, Social Management, Brazil.

\section{INTRODUÇÃO}

Na primeira década do século XXI, vários países da América Latina adotaram o "enfoque

\footnotetext{
${ }^{1}$ Pesquisador do CIRAD UMR Tetis, Montpellier, França; Professor Associado da Universidade Federal do Pará (UFPA). Email: marcpiraux@uol.com.br

${ }^{2}$ Professor Titular de Antropologia e Professor Permanente do Programa de Pós-Graduação em Ciências Sociais (PPGS) da Universidade Federal de Campina Grande (UFCG). E-mail: caniello@ufcg.edu.br
} 
territorial" como estratégia de execução de políticas públicas para o desenvolvimento rural, um panorama institucional em que os atores locais eram instados a pensar e planejar o seu próprio futuro, decidindo sobre suas demandas prioritárias, definindo projetos voltados a atingir os objetivos planejados e avaliando e monitorando a elaboração e execução desses projetos. Tudo isso num ambiente participativo e democrático. Foi um grande desafio, pois implementar o desenvolvimento dessa maneira inovadora exigia mudanças significativas de comportamento político e administrativo por preconizar uma nova divisão de funções e do poder (Corezola et al, 2010), o que implicava o fortalecimento dos grupos sociais locais e suas organizações, na consolidação das ações coletivas, bem como na articulação e sintonia entre as diferentes dimensões do desenvolvimento (Bonnal e Kato, 2010).

Esse processo foi fruto da emergência de governos populares na América Latina, os quais, rompendo com o formulário neoliberal hegemônico nos anos 1990 e se colocando na trilha do combate à pobreza e à desigualdade, "passaram a criar ou a fortalecer arranjos institucionais de participação social na gestão pública, visando diminuir a distância entre o Estado e a sociedade” (Silva, 2009, p. 9). Esse processo teve como fundamento o que os cientistas políticos chamam de democracia direta ou participativa, uma forma de superar "o contraste entre os ideais democráticos e a democracia real" (Bobbio, 2000, p. 33)

No Brasil, com a ascensão de Luís Inácio Lula da Silva, do Partido dos Trabalhadores (PT), à Presidência da República em 2003, o governo brasileiro assumiria uma agenda bastante proativa em relação ao desenvolvimento rural brasileiro, focando-se, entre outras diretrizes, no enfrentamento da questão agrária, no apoio à agricultura familiar e na adoção do enfoque territorial. Para tal, no primeiro ano de seu governo, reestabeleceu o Ministério do Desenvolvimento Agrário (MDA), em cuja estrutura foi criada a Secretaria de Desenvolvimento Territorial (SDT), responsável pela elaboração e gestão do Programa Nacional de Desenvolvimento Sustentável dos Territórios Rurais (PRONAT).

Em linhas gerais, essa nova estratégia estabeleceu a delimitação de "territórios rurais" envolvendo conjuntos de municípios "formados em um processo histórico de construção de identidades" (Oliveira, 2008 , p. 7) e a constituição, em cada qual, de uma instância deliberativa, denominada "colegiado" ou “fórum", formada paritariamente por representantes da sociedade civil (associações, sindicatos, ONGs, cooperativas, etc.) e dos governos federal, estadual e municipal. Era nesses dispositivos de governança territorial que se efetivava o chamado "ciclo de gestão social" (Oliveira e Valencia, 2012), isto é, o processo participativo de debate, disputas e concertação sobre o planejamento, implementação, avaliação 
e monitoramento de ações e políticas públicas voltadas para o desenvolvimento rural ${ }^{3}$, processo esse que deslindaria uma dialética ativa, produtiva e progressiva entre identidade, participação social e desenvolvimento rural sustentável.

O PRONAT vigorou por 13 anos e foi interrompido pelo governo Temer, que emergiu do golpe parlamentar impetrado em agosto de 2016, contra a presidenta Dilma Rousseff, também do PT. A partir de então, as forças reacionárias encasteladas nos poderes formais e informais da República passaram a promover um amplo processo de desmonte das políticas públicas inclusivas e progressistas, implementadas pelos governos do PT. No âmbito do desenvolvimento rural, tudo começou pela a extinção do MDA, uma das primeiras medidas do governo Temer, mantida pelo governo Bolsonaro, eleito presidente da República em 2018.

Portanto, atualmente o PRONAT não existe mais, embora alguns colegiados ainda se mantenham em funcionamento, principalmente para tratar de projetos do $\mathrm{PROINF}^{4}$ em andamento, aprovados em anos anteriores e com "restos a pagar". Mas tirar ensinamentos da experiência inovadora da governança territorial nas áreas rurais do Brasil é um desafio importante, em vista de sua amplitude e dos resultados positivos atingidos 5 .

Nesse sentido, este trabalho tem como objetivo avaliar os avanços e entraves da governança territorial no Brasil por meio da análise da implementação do PRONAT, visando propor alternativas para um ajuste de rumos em favor de sua retomada. Para tanto, parte-se da análise do Índice de Gestão Social (IGS), inferido com base em 785 questionários aplicados a membros ativos dos colegiados de 33 Territórios da Cidadania, confrontando-o com evidências empíricas e analíticas trabalhadas a partir de dados e reflexões produzidas em duas pesquisas nacionais realizadas sobre a temática entre 2010 e $2017^{6}$.

\section{A POLÍTICA TERRITORIAL NO BRASIL}

Uma característica proeminente na reorganização do Estado brasileiro após a derrocada da

\footnotetext{
${ }^{3}$ Para a SDT/MDA, a "gestão social" está relacionada ao empoderamento da sociedade, com o estabelecimento de compromissos entre o público e o privado, mediante a garantia da participação social na gestão pública que requer sistemas descentralizados, baseado em forte participação, maior densidade de informação, parcerias e articulações em rede, transparência e efetiva participação da sociedade, implicando e ampliando os níveis de capacidades humanas, sociais e organizacionais do Território (BRASIL, 2009, p.12).

${ }^{4} \mathrm{O}$ "PROINF - Apoio a Projetos de Infraestrutura e Serviços em Territórios Rurais", principal sustentáculo do PRONAT, era uma Ação prevista nos Planos Plurianuais (PPAs), Leis de Diretrizes Orçamentárias (LDOs) e Leis Orçamentárias Anuais (LOAs) durante os governos Lula e Dilma, que visava financiar projetos em várias áreas do desenvolvimento rural com recursos do Tesouro Nacional a fundo perdido.

${ }^{5}$ Cf. Caniello, 2016.

${ }^{6}$ Chamada Pública MDA/SDT/CNPq - Gestão de Territórios Rurais No 05/2009 (27 equipes em 37 territórios) - "Projeto Células" e Chamada Pública CNPq/MDA/SDT/SPM-PR No 011/2014 - Apoio à implantação e manutenção de Núcleos de Extensão em Desenvolvimento Territorial (54 equipes em 186 territórios) - "Projeto Nedets".
} 
ditadura militar foi a institucionalização da participação dos cidadãos na gestão das políticas públicas. De fato, com a promulgação da Constituição Federal de 1988, os espaços para a participação da sociedade civil na definição e implementação das políticas públicas no Brasil ampliaram-se significativamente, resultado da própria luta pela redemocratização do país e fruto da atuação decisiva da sociedade civil organizada nesse processo (Doimo, 1995, Gohn, 2001, p. 52, Santos; Avritzer, 2002, p. 65, Silva, 2009, p. 13). A regulamentação da diretriz constitucional participativa apontou para a formação de conselhos gestores de políticas públicas, estruturados de forma hierarquizada nos níveis nacional, estadual e municipal, em diversas áreas, como saúde, trabalho, educação, assistência e previdência social, direitos do cidadão, cultura, ciência e tecnologia, meio ambiente, e desenvolvimento rural (Gohn, 2001, p. 8687).

Os Conselhos Municipais de Desenvolvimento Rural (CMDRs) se multiplicaram exponencialmente a partir de 1997, depois da criação do Programa Nacional de Fortalecimento da Agricultura Familiar (PRONAF), cujos recursos da linha infraestrutura e serviços só poderiam ser acessados pelos municípios que os constituíssem. Embora seu "potencial de transformação política" (Abramovay, 2001, p. 121) tenha dado alguns bons frutos no sentido da democratização das políticas públicas de desenvolvimento rural, os CMDRs - como também os outros conselhos setoriais apresentaram uma série de dilemas e paradoxos que perverteriam seus objetivos mais amplos, ressaltando-se o frequente processo de "prefeiturização" (Jara, 1998, p. 235), isto é, a submissão da agenda construída participativamente aos interesses dos grupos políticos hegemônicos nos municípios, o chamado "poder local".

Diante dessa realidade, a partir de 2003 o governo federal optou por redefinir o recorte das arenas deliberativas locais por meio do PRONAT e, assim, “os Territórios 'despertavam' como um espaço intermediário entre os municípios e os estados, possibilitando a participação da sociedade civil vinculada à agricultura familiar nas decisões de desenvolvimento" (Grisa; Schneider, 2015, p. 34). Nesse sentido, os então chamados "Territórios de Identidade" foram definidos levando-se em conta um conjunto objetivo de critérios ${ }^{7}$ e os colegiados participativos paritários foram compostos por representantes da sociedade civil e dos governos federal, estadual e municipal. Com esse novo arranjo, procurava-se superar o caráter setorial das políticas públicas de desenvolvimento rural no país e aprofundar a participação dos atores sociais em sua implementação. Esse processo de inovação institucional culminaria na criação do Programa Territórios da Cidadania (PTC) em 2008, que articulava 22 ministérios, visando apoiar de maneira emergencial e com ações mais articuladas os territórios rurais

\footnotetext{
${ }^{7}$ Cf. Delgado e Leite, 2015: 249.
} 
economicamente mais fragilizados.

Em 2016, havia 239 Territórios Rurais no Brasil - entre os quais 120 Territórios da Cidadania -, abrangendo uma área de $6.474 .410 \mathrm{Km}^{2}$ (76\% do território nacional), reunindo 3.591 municípios (64\%), com 76,7 milhões de habitantes, sendo 22,5 milhões de habitantes da zona rural (75,5\% da população rural), 3.513.414 estabelecimentos da Agricultura Familiar (80\%), 10.114 .982 pessoas ocupadas na Agricultura Familiar (79\%), 812.283 famílias de assentados da Reforma Agrária (84\%), 2.093 comunidades quilombolas (87\%) e 652.582 famílias de pescadores (66\%) (Brasil, 2009b; Brasil, 2011).

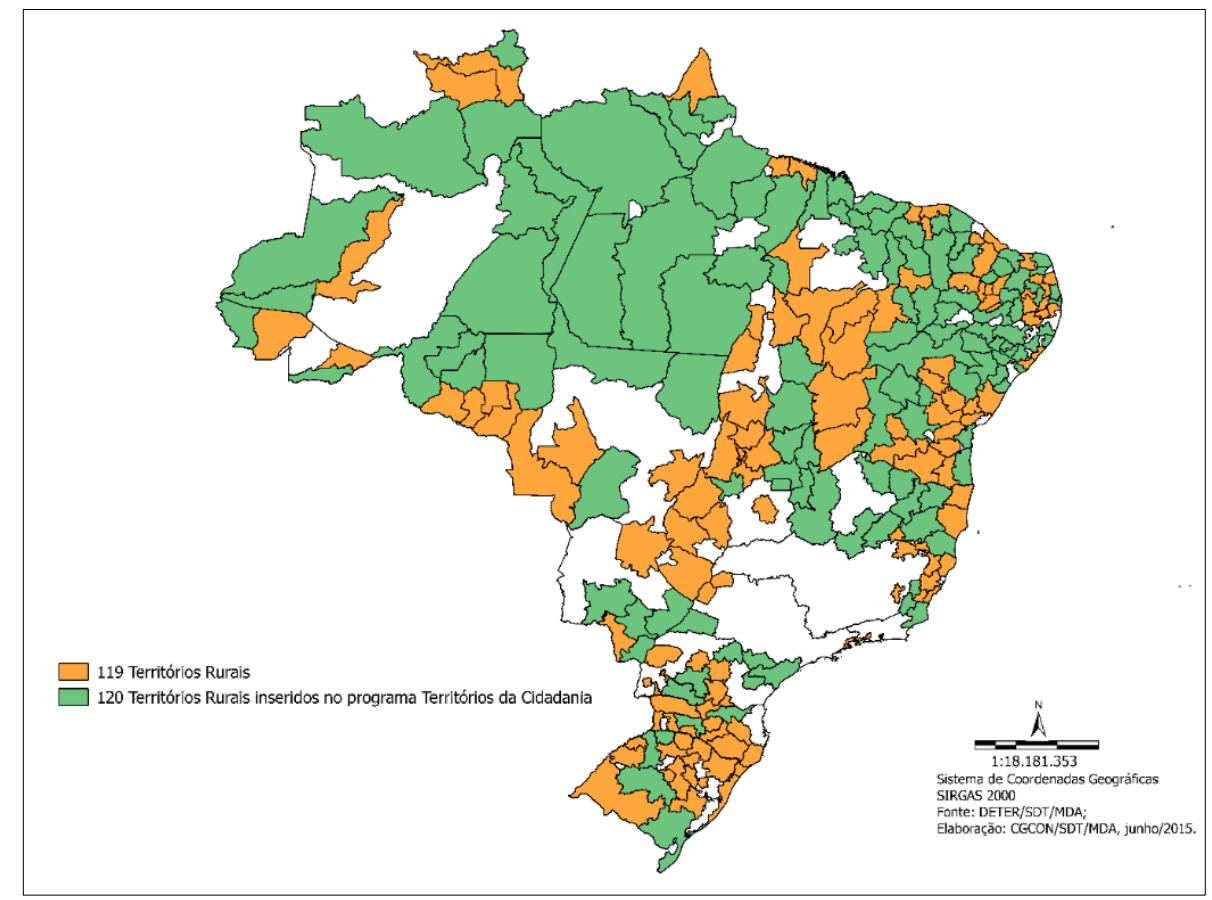

Figura 1 - Territórios Rurais no Brasil (Fonte: SDT/MDA, 2015)

Entre 2003 e 2015, o PROINF repassou R $\$ 3,3$ bilhões $^{8}$ para 8.141 projetos aprovados e monitorados pelos colegiados territoriais, dos quais $74 \%$ encontravam-se concluídos em meados de $2016^{9}$.

\section{REFERENCIAIS DE ANÁLISE}

O conceito de governança territorial é polissêmico (Simoulin, 2007), pois traduz usos variados em contextos e realidades muito diferentes. Como construção social que representa o território, ele expressa práticas evolutivas de negociação e participação. Assim, a governança territorial corresponde a um processo de planejamento e gestão de dinâmicas territoriais que dá prioridade a uma ótica inovadora,

\footnotetext{
${ }^{8}$ Em valores deflacionados pelo IGP-DI, da Fundação Getúlio Vargas (FGV), para 31/12/2015.

${ }^{9}$ Conforme dados da Caixa Econômica Federal (relatório gerado em março de 2016) e CGMA/SDT/MDA (relatório gerado em maio de 2016).
} 
partilhada e colaborativa, por meio de relações horizontais (Dallabrida, 2015). Essa situação vem do “inédito deslocamento dos modos de legitimação do político, que iriam do mais distante para o mais próximo" (Pasquier; Weisbein, 2007, p. 211).

A governança territorial questiona a lógica top-down, que considera apenas os níveis locais como receptáculos das decisões e traduz, assim, uma situação de "conflito das fronteiras tradicionais e de porosidade crescente entre os setores, níveis territoriais e os diferentes espaços da atividade profissional" (Pasquier e Weisbein, 2007, p. 216). Enfim, a governança territorial constitui um possível modo de realização de um novo projeto de sociedade, na qual, com respeito a um contrato social atualizado, a participação se juntaria à representação democrática (Caillebosse, 2007).

Os dispositivos de governança são destinados a organizar a discussão e as trocas entre atores para definir objetivos comuns, produzir normas aceitas e legitimadas, traduzi-las em regras e implementa-las (Piraux et al, 2010). Constituídos a partir de arranjos institucionais, eles legitimam as decisões a partir de regras jurídicas claras, respeitando os interesses de cada grupo, enfrentando os conflitos e definindo uma visão compartilhada dos problemas e potenciais de desenvolvimento dos territórios.

Nesse panorama, criar um sistema de informação se torna imprescindível para se avaliar o desempenho dos dispositivos de governança, o que requer o enfrentamento de três desafios fundamentais: (i) considerando que muitos estudos são localizados (Rey-Valette; Mathé, 2012; Butto; Bemerguy , 2014, p. 15) e que raramente há processos de avaliação em nível nacional, é preciso integrar a avaliação da diversidade de situações observadas; (ii) a avaliação tem que se fundar num conjunto de indicadores, formando assim um índice suscetível de traduzir a complexidade do funcionamento e o desempenho dos dispositivos de governança; enfim, (iii) é preciso também articular esses indicadores com outros que traduzem o contexto institucional e social no qual a governança se efetive.

De fato, a metodologia clássica recorre a indicadores e, nesse sentido, foi elaborado o Índice de Gestão Social (IGS) ${ }^{10}$, que tem o propósito de exprimir, de maneira mais aproximada à realidade, o funcionamento dos colegiados territoriais. O Índice é inferido a partir do cálculo de nove indicadores, agrupados em três dimensões (Quadro 1), cada uma sendo a média dos seus próprios indicadores. O IGS resulta da média dos valores dessas três dimensões e varia entre 0 (zero) e 1 (um), sendo o resultado classificado nas seguintes categoriais: $0,00-0,20=$ Baixo; 0,20 - 0,40= Médio Baixo; 0,40 - 0,60= Médio; $0,60-0,80=$ Médio Alto; $0,80-1,00=$ Alto.

${ }^{10}$ O IGS foi elaborado por um Grupo de Trabalho constituído por coordenadores de Células de Acompanhamento e Informação (CAI), instituídas pela Chamada Pública MDA/SDT/CNPq No 05/2009, técnicos e colaboradores da Secretaria de Desenvolvimento Territorial (SDT) do Ministério do Desenvolvimento Agrário, do qual os autores deste trabalho fizeram parte. 
Quadro 1 - Composição do Índice de Gestão Social (IGS)

\begin{tabular}{|l|l|}
\hline \multicolumn{1}{|c|}{ Dimensões } & \multicolumn{1}{c|}{ Indicadores } \\
\hline \multirow{2}{*}{ 1. Participação e Mobilização } & 1.1. Capacidade de mobilização \\
\cline { 2 - 3 } & 1.2. Capacidade de decisão dos diferentes segmentos \\
\hline \multirow{4}{*}{ 2. Estrutura de governança } & 2.1. Capacidade de gestão do colegiado \\
\cline { 2 - 2 } & 2.2. Desempenho do funcionamento \\
\hline \multirow{4}{*}{ 3. Impactos do funcionamento } & 3.1. Legitimidade \\
\cline { 2 - 2 } & 3.2. Exercício do poder \\
\cline { 2 - 2 } & 3.3. Aprendizagem \\
\cline { 2 - 2 } & 3.4. Territorialização das políticas públicas \\
\cline { 2 - 2 } & 3.5. Melhoramento dos laços sociais \\
\hline
\end{tabular}

Fonte: SGE/MDA (2014)

O questionário do IGS foi aplicado a 785 representantes de organizações (públicas, privadas e da sociedade civil) de 33 Territórios da Cidadania que tinham uma participação ativa nos colegiados territoriais, de acordo com avaliação conjunta realizada pelas "Células de Acompanhamento e Informação" (CAI) e os Núcleos Diretivos dos colegiados.

\section{O ÍNDICE DE GESTÃO SOCIAL}

O valor obtido para o IGS (Quadro 2) é médio $(0,559)$ e os valores das três dimensões foram: 0,522 para a "participação e mobilização", 0,503 para "estrutura de governança", também médios, e 0,699 para "impactos do funcionamento", médio alto. Isso significa que os respondentes valorizam os resultados da gestão social, embora demonstrem-se críticos em relação a seus condicionantes.

\begin{tabular}{|l|c|c|c|c|}
\multicolumn{2}{c}{ Quadro $2-$ O IGS em 33 Territórios da Cidadania (a escala varia de 0 a 1) } \\
\cline { 3 - 5 } \multicolumn{1}{|c}{ Medidas } & \multirow{2}{*}{ IGS } & $\begin{array}{c}\text { Participação e } \\
\text { Mobilização }\end{array}$ & $\begin{array}{c}\text { Estrutura de } \\
\text { governança }\end{array}$ & $\begin{array}{c}\text { Impactos do } \\
\text { funcionamento }\end{array}$ \\
\hline Índice/Indicador & 0,559 & 0,522 & 0,503 & 0,699 \\
\hline Classificação & Médio & Médio & Médio & Médio-alto \\
\hline Desvio padrão (DP) & 0,083 & 0,114 & 0,074 & 0,067 \\
\hline Valor mínimo & 0,353 & 0,288 & 0,327 & 0,508 \\
\hline Valor máximo & 0,688 & 0,735 & 0,620 & 0,842 \\
\hline
\end{tabular}

Fonte: Elaboração própria, com dados do SGE/MDA (2014)

A variação dos escores do IGS entre os territórios pesquisados (mínimo de 0,353 e máximo de 0,688), mostra uma diversidade de situações, mas a maioria não apresenta grandes problemas, pois em 12 territórios $(36 \%)$ o IGS foi médio-alto $(\geq 0,60)$, e em 14 territórios $(42 \%)$ foi médio, mas com viés 
positivo $(0,50$ - 0,59), enquanto em 5 territórios (15\%) o IGS foi médio com viés negativo $(0,40$ - 0,49) e tão somente 2 territórios (6\%) apresentaram um IGS médio baixo $(0,20-0,39)$.

Em relação à variação dos índices apurados para as três dimensões, percebe-se que "participação e mobilização" apresenta um desvio padrão importante $(0,114)$, enquanto as outras dimensões variam menos, sendo que "impactos do funcionamento" obteve o menor desvio padrão $(0,067)$. Assim, percebes que há uma grande concordância acerca dos bons resultados da gestão social, enquanto a base do ciclo de gestão social, isto é, a mobilização e participação dos membros dos colegiados, varia bastante de território para território ${ }^{11}$.

\section{Os dispositivos de governança territorial}

De maneira a melhor avaliar os meandros do ciclo de gestão social, as suas duas dimensões constitutivas - "mobilização e participação" e "estrutura de governança" - que obtiveram escores gerais médios (Quadro 3) serão esmiuçadas a seguir.

Quadro 3 - As dimensões constitutivas do dispositivo de governança (a escala varia de 0 a 1 )

\begin{tabular}{|l|l|l|l|c|c|c|c|}
\hline \multicolumn{1}{|c|}{ Dimensão } & Valor & Nível & \multicolumn{1}{|c|}{ Indicadores } & Valor & DP & Min & Max \\
\hline $\begin{array}{l}\text { Mobilização e } \\
\text { Participação }\end{array}$ & 0,522 & \multirow{2}{*}{ Médio } & Capacidade de Mobilização & 0,540 & 0,175 & 0,18 & 0,82 \\
\cline { 4 - 8 } & & Capacidade de Decisão & 0,504 & 0,103 & 0,23 & 0,70 \\
\hline $\begin{array}{l}\text { Estrutura de } \\
\text { Governança }\end{array}$ & 0,503 & \multirow{2}{*}{ Médio } & Capacidade de Gestão & 0,538 & 0,062 & 0,39 & 0,64 \\
\cline { 4 - 8 } & & Desempenho do funcionamento & 0,468 & 0,098 & 0,25 & 0,63 \\
\hline
\end{tabular}

Fonte: Elaboração própria, com dados do SGE/MDA (2014)

Há que se observar que os indicadores que compõem essas dimensões variam de colegiado para colegiado, especialmente as capacidades de mobilização $(\mathrm{DP}=0,175)$, decisão $(\mathrm{DP}=0,103) \mathrm{e}$ desempenho do funcionamento ( $\mathrm{DP}=0,098)$, o que impõe a necessidade de estudos mais aprofundados que possam explicar as causas dessa variação, mas, como já ressaltado na nota 11, não há qualquer correlação entre as variações observadas e as regiões geográficas dos colegiados.

Mobilização e participação

O indicador "capacidade de mobilização" - medido pela própria avaliação que os respondentes tinham dela, considerando-se a frequência dos encontros da plenária (cada quatro ou cinco meses em média), do núcleo dirigente (cada um ou dois meses em média) ou do núcleo técnico (cada quatro meses

\footnotetext{
${ }^{11}$ A regressão estatística não estabeleceu correlações significativas entre os índices apurados e as regiões em que os colegiados estavam instalados.
} 
em média), quando este último existia - obteve um escore médio $(0,540)$. Cabe ressaltar que o desvio padrão desse indicador é o maior obtido entre os quatro apurados, o que demonstra que esse fator é muito diferente segundo os territórios.

Quanto ao indicador "capacidade de decisão" dos representantes das instituições presentes nas reuniões do colegiado, este também é avaliado como médio $(0,504)$, mas a tabulação dos microdados revelou o baixo desempenho de um número significativo de segmentos sociais, principalmente os membros dos governos estadual e municipal, das entidades religiosas e de comunidades tradicionais. Em relação aos representantes dos governos municipais, seu mau desempenho está relacionado ao absenteísmo, à rotatividade e à falta de autonomia que os representantes das prefeituras possuem em função da não participação dos prefeitos nas reuniões, o mesmo acontecendo com os representantes dos governos estaduais. Ademais, nota-se que, das três esferas de poder público, a participação dos municípios é menor que a dos representantes dos estados e do governo federal, o que é um fato inusitado no marco da gestão territorial.

Por outro lado, a participação dos sindicatos, associações, movimentos sociais e ONGs é considerada como boa, o que evidencia a forte capacidade de tomada decisão que os membros da sociedade civil possuíam nos colegiados territoriais. Isso se explica pelo papel que essas organizações vinham desempenhando nos territórios antes e durante a implementação do PRONAT.

Os dados mostram também que o valor baixo do indicador "capacidade de decisão" decorre de outros fatores importantes, como a ausência de atores e instituições que os respondentes consideram como estratégicos, especialmente prefeitos e secretários municipais, e a existência de grupos hegemônicos no colegiado que concentravam a decisão, fragilizando a qualificação do debate e a tomada de decisões.

Quando instados a avaliar se houve mudanças quanto a esses aspectos, os respondentes afirmaram que a participação da sociedade civil em geral melhora um pouco no decorrer do tempo (exceto para as entidades religiosas), o que se revela um fator favorável. Todavia o mesmo não ocorre com os representantes do poder público.

\section{Estrutura de governança}

A capacidade média de gestão do colegiado $(0,538)$ é detalhada no Quadro 4, que estratifica todas as atividades que entraram no cálculo do indicador, listando-as em ordem decrescente. 
Quadro 4-Capacidade de gestão dos colegiados por atividade desenvolvida

\begin{tabular}{|l|l|}
\hline \multicolumn{1}{|c|}{ Capacidade } & \multicolumn{1}{c|}{ Atividade } \\
\hline Boa & Fazer um debate coletivo sobre o desenvolvimento rural no Território \\
\hline Média a boa & Animar o colegiado (tomada de palavra, direção das reuniões, pauta) \\
\hline & Construir objetivos comuns \\
& Definir regras coletivas de funcionamento \\
& Lidar com os grupos de interesse \\
& Encaminhar a resolução de problemas \\
& Definir as responsabilidades de cada um \\
& Cumprir regras definidas e acordadas coletivamente \\
& Resolver conflitos \\
& Acompanhar e avaliar as ações desenvolvidas \\
\hline
\end{tabular}

Fonte: Elaboração própria, com dados do SGE/MDA (2014)

Em linhas gerais, percebe-se que, na medida em que se vai do campo das ideias e dos "meios" para o campo da prática e dos "fins", as capacidades vão enfraquecendo"12. Assim, "fazer um debate coletivo" e "animar o colegiado" se configuram como as melhores capacidades, enquanto "resolver conflitos" e "acompanhar e avaliar as ações", as piores. No mesmo diapasão, as capacidades de "construir objetivos", "definir regras" e "lidar com grupos de interesse" sobrepujam ações mais práticas como “encaminhar a resolução de problemas", "definir responsabilidades" e "cumprir regras".

Esses resultados demonstram problemas de gestão no processo da governança, pois as capacidades que foram avaliadas como "médias" são muito importantes para a consolidação dos arranjos institucionais, particularmente aquela que apresentou o pior desempenho, a capacidade de acompanhar e avaliar as ações desenvolvidas, prática fundamental para o aperfeiçoamento de processos e o ajuste de rumos. Por outro lado, a dificuldade de definir responsabilidades individuais, cumprir regras acordadas coletivamente e os problemas encontrados no trato dos conflitos aduzem à falta de cultura organizacional. Assim, compreende-se porque o indicador pior avaliado na estrutura da governança territorial seja exatamente o "desempenho do funcionamento" do colegiado $(0,468)$, cujos problemas apontados numa escala que vai de 1 (o problema "não prejudica o funcionamento do colegiado") a 5 (o problema “prejudica muito o funcionamento do colegiado") evidenciam a gravidade da situação, como se pode verificar no Quadro 5.

\footnotetext{
${ }^{12}$ Já havíamos demonstrado essa tendência quando analisamos a gestão social no Território da Borborema (Caniello; Piraux; Bastos, 2013b).
} 
Quadro 5 - Problemas de gestão dos colegiados territoriais (a escala varia de 0 a 5)

\begin{tabular}{|l|c|}
\hline \multicolumn{1}{|c|}{ Problema } & Média \\
\hline Baixa participação dos gestores públicos nas reuniões do colegiado & 4,2 \\
\hline Rotatividade dos membros do colegiado & 3,7 \\
\hline Falta de assessor técnico & 3,6 \\
\hline Baixa participação dos agricultores & 3,6 \\
\hline Influência política & 3,5 \\
\hline Baixa capacidade técnica em relação a projetos & 3,5 \\
\hline O colegiado não é ouvido em outras instâncias & 3,5 \\
\hline
\end{tabular}

Fonte: Elaboração própria, com dados do SGE/MDA (2014)

A baixa participação dos prefeitos foi o principal problema apontado porque, na opinião dos entrevistados, determinadas decisões só podem ser tomadas com a presença deles, como, por exemplo, a doação de um terreno ou o cumprimento de contrapartidas para a realização dos projetos. Esse problema se relaciona com um fato absolutamente deletério na governança territorial: os projetos são decididos democraticamente nas plenárias territoriais, mas, por força legal, estes só podem ser executados por órgãos da administração pública.

Associado ao absenteísmo dos prefeitos, outros problemas de participação foram destacados, como a rotatividade dos membros do segmento governamental, algo que afetava diretamente a dinâmica e gestão do colegiado, pois prejudicava a continuidade das ações. Por outro lado, evidenciou-se a baixa participação dos próprios agricultores, base social dos colegiados, em geral representados por suas lideranças, o que coloca em pauta os dilemas da mediação. Em ambos os casos, o ciclo de gestão social via-se fragilizado pelo fato de não haver regras de repasse das informações do representante para os representados ou a suas instituições e organizações.

Também foram ressaltados problemas advindos da influência do poder local nos territórios, onde as lutas partidárias envenenam as relações entre os participantes dos colegiados e motivações políticas movem peças importantes no processo decisório. Assim, era frequente a configuração de grupos políticos hegemônicos na governança territorial, o que pervertia o sentido democrático e inclusivo do ciclo de gestão social, como já demonstramos anteriormente (Caniello; Piraux; Bastos, 2012, p. 20; 2013, p. 97; 2013b, p. 32; 2014, p. 26 e 45). Ainda no campo político, o fato do colegiado não ser ouvido em outras instâncias revela um problema de legitimidade que fragilizava ainda mais o ciclo de gestão social.

Finalmente, mas não menos importante, foram colocados problemas técnicos, seja pela falta de assessores para cumprirem tarefas administrativas e de animação do colegiado, seja quanto à baixa capacidade técnica dos membros, o que fez com que vários projetos idealizados pelo colegiado não ganhassem corpo em função de carências de planejamento, acompanhamento e monitoramento.

Não resta dúvida que esses problemas afetavam consideravelmente o desempenho do colegiado, 
especialmente porque a maioria deles provocava o enfraquecimento de sua credibilidade e de seu poder de ação, o que resultava em um processo frágil e deficiente de articulação, afetando negativamente a estratégia territorial como um todo.

\section{Impactos}

Apesar dos resultados médios obtidos nas duas primeiras dimensões do IGS, a pesquisa verificou que os impactos do funcionamento dos colegiados territoriais foram bastante valorizados pelos respondentes, o que resultou num escore para essa dimensão de 0,699 , classificado como "médio alto", cujo detalhamento está sintetizado no Quadro 6.

Quadro 6 - Impacto do funcionamento dos colegiados territoriais (a escala varia de 0 a 1)

\begin{tabular}{|l|c|c|c|c|c|}
\hline Indicadores & Escore & Nível & DP & Min & Max \\
\hline Legitimidade & 0,658 & Médio Alto & 0,097 & 0,402 & 0,857 \\
\hline Exercício do poder & 0,681 & Médio Alto & 0,117 & 0,366 & 0,905 \\
\hline Aprendizagem & 0,678 & Médio Alto & 0,060 & 0,554 & 0,858 \\
\hline Territorialização das políticas públicas & 0,617 & Médio Alto & 0,117 & 0,319 & 0,786 \\
\hline Melhoramento dos laços sociais & 0,853 & Alto & 0,082 & 0,534 & 0,970 \\
\hline
\end{tabular}

Fonte: Elaboração própria, com dados do SGE/MDA (2014)

O indicador "legitimidade do colegiado" representa o reconhecimento dos respondentes à pertinência e importância do dispositivo de governança para o desenvolvimento dos territórios, e o nível médio-alto obtido significa que os atores reconheciam que a participação no colegiado oferecia algum benefício para as suas próprias instituições. Entretanto, sabendo-se que um dos maiores problemas ressaltados pelos mesmos entrevistados era que "o colegiado não é ouvido em outras instâncias", esse resultado traduz, tão somente, uma legitimidade autoconferida.

Segundo $80 \%$ dos respondentes, os colegiados possibilitaram uma repartição mais equilibrada do poder nos territórios e asseguraram um equilíbrio maior entre os grupos de interesse presentes no dispositivo de governança, enquanto para $70 \%$ o ciclo de gestão social propiciou uma renovação das lideranças. Isso tem que ser relativizado, pois, como visto anteriormente, os respondentes destacaram a cristalização de grupos hegemônicos nos colegiados, o que de certa forma contradita essa avaliação positiva. Seja como for, sabe-se que atores vinculados ao ciclo de gestão social conseguiram assumir posições de liderança político-administrativa nos municípios e estados, inclusive por meio eleitoral.

O indicador "aprendizagem” apresentou também uma boa avaliação, obtendo um escore de 0,678, sendo três fatores melhor avaliados: "uma visão mais clara dos desafios da região", "uma melhor leitura das dinâmicas atuais do território", e "entender melhor as políticas públicas”, conforme se pode observar 
no Quadro 7.

Quadro 7 - Resultados do processo de aprendizagem (a escala varia de 0 a 5)

\begin{tabular}{|l|c|}
\hline \multicolumn{1}{|c|}{ Fator } & Média \\
\hline Melhor leitura das dinâmicas atuais do território & 4,0 \\
\hline Visão mais clara dos desafios da região & 3,9 \\
\hline Entender as políticas públicas & 3,9 \\
\hline Entender as percepções de uma gestão social das políticas públicas & 3,8 \\
\hline Entender as percepções dos grupos de interesse & 3,7 \\
\hline Capacidade de negociação & 3,7 \\
\hline Capacidade de intercâmbios de experiências e troca de conhecimento & 3,7 \\
\hline Capacidade de lidar com os conflitos & 3,6 \\
\hline Capacidade de definir, implementar e avaliar propostas de projeto & 3,6 \\
\hline Diálogo com o Estado & 3,3 \\
\hline
\end{tabular}

Fonte: Elaboração própria, com dados do SGE/MDA (2014)

Por outro lado, para os respondentes, o que menos evoluiu no processo de aprendizagem propiciado por sua participação na instância territorial, foi o "diálogo com o Estado", o que demonstra que os problemas de legitimidade apontados anteriormente se configuraram realmente num entrave importante para o ciclo de gestão social. Contudo, os resultados evidenciam um processo de aprendizagem bastante eficaz, ainda que exista certa dificuldade de colocar em prática essa aprendizagem, como mostram os resultados obtidos ao nível dos problemas enfrentados na gestão dos colegiados.

Para $80 \%$ dos entrevistados, um dos principais impactos do funcionamento dos colegiados foi a territorialização das políticas públicas, enquanto para 70\% deles o trabalho do colegiado possibilitou uma articulação melhor com as políticas dos governos estaduais e, para 60\%, ele redundou em mudanças nas políticas municipais.

Enfim, o indicador que obteve o melhor escore nessa dimensão e em toda a pesquisa foi o "melhoramento dos laços sociais", que atingiu a cifra de 0,853 , o que representa um nível "alto" de impacto positivo. De fato, segundo os respondentes, o colegiado influenciou sobremaneira a melhoria das relações sociais e de cooperação entre os atores locais, bem como as redes sociais existentes. Em virtude disso, $82 \%$ dos entrevistados afirmaram que seu sentimento de pertença ao território aumentou de maneira expressiva, e $87 \%$ que o fato de fazer parte do colegiado contribuiu para modificar a maneira de pensar e agir dos participantes.

\section{AVANÇOS E ENTRAVES DA GOVERNANÇA TERRITORIAL}

Confrontando-se a análise do IGS com evidências empíricas e analíticas oriundas das pesquisas 
nacionais realizadas entre os anos de 2010 e 2017 e já trabalhadas em diversas ocasiões (Caniello, 2016; Caniello; Piraux; Bastos, 2012, 2013, 2013b, 2014; Piraux e Caniello, 2016; Piraux et al, 2017; Caniello e Teixeira, 2017; Teixeira e Caniello, 2016, 2018; Caniello; Piraux; Rambo, 2012), conclui-se que a governança territorial no PRONAT apresentou avanços e entraves, os quais serão apresentados nesta seção.

O primeiro avanço são os resultados concretos da política territorial, consubstanciados nos 8.141 projetos financiados pelo PROINF, totalizando um investimento de 3,3 bilhões de reais, embora muitos desses projetos apresentem problemas de execução e funcionamento (Teixeira e Caniello, 2016). Registre-se, contudo, que, em pesquisa desenvolvida em 2015 por meio da realização de grupos focais com 81 lideranças de 8 colegiados, $86 \%$ dos entrevistados ressaltaram que a política territorial provocou impactos positivos nos territórios, cuja maioria ressaltou os investimentos nos ativos territoriais como os mais importantes, quais sejam: valorização e desenvolvimento da agricultura familiar, mudanças na estrutura de produção e comercialização, investimento público direcionado às necessidades do território e desenvolvimento da educação do campo (Valencia et al, 2015).

Também se ressalta, como avanço, a territorialização de várias políticas públicas (indicador de 0,68), notadamente nos programas de compras governamentais (PAA e PNAE) e, associado a eles, a territorialização do Sistema de Inspeção Sanitária com a criação do SUASA (Sistema Unificado de Atenção à Sanidade Agropecuária), reivindicação de um conjunto importante de colegiados territoriais. Também houve avanços significativos na territorialização de ações de educação, como as Escolas Família Agrícola (EFAs) e o PRONATEC Campo (Programa Nacional de Acesso ao Ensino Técnico e Emprego).

Outros avanços importantes foram decorrentes da própria dinâmica propiciada pelo ciclo de gestão social. Primeiramente, a ampliação do controle democrático sobre as políticas públicas para o desenvolvimento rural, decorrente da participação da sociedade civil nos colegiados. Em segundo lugar, o empoderamento da sociedade civil, seja porque os atores e suas organizações se reconheciam legítimos em decorrência dos resultados positivos do ciclo de gestão social, seja porque esses atores conseguiram assumir posições de liderança político-administrativa nos municípios e estados, como já indicado anteriormente. Em terceiro lugar, pela aprendizagem decorrente do processo participativo, já que os atores reconheceram ganhos no conhecimento das dinâmicas territoriais, dos desafios do desenvolvimento e das políticas públicas (ver Quadro 7). Finalmente, e talvez o mais importante, o melhoramento dos laços sociais - entre todos os indicadores, o que obteve melhor escore - mostra que o ciclo de gestão social favorece a cooperação entre os atores, o que alimenta o seu sentimento de pertença (identidade) e fortalece o capital social, base do desenvolvimento territorial, processo que confirma a 
possibilidade de se estabelecer um "círculo virtuoso do desenvolvimento rural” a partir do ciclo de gestão social.

Mas, como se observou neste trabalho, vários entraves se interpuseram a esses avanços. Primeiramente, os limites organizacionais dos colegiados: a falta de uma estrutura administrativa ou de assessoria estável provocava improvisações em procedimentos básicos, como a convocação de reuniões, redação de atas, prestações de contas, atualização de cadastros e listas de endereços, manutenção de um arquivo atualizado e a própria comunicação entre a coordenação, os membros do colegiado e a sociedade, o que resultava em problemas de mobilização, participação e legitimação do colegiado ${ }^{13}$.

Em segundo lugar, evidenciaram-se muitos os limites na participação dos membros do colegiado, em face do absenteísmo e da rotatividade dos mesmos, principalmente os representantes do poder público, ocasionada pela alternância no poder e mesmo por mudanças ocasionais no curso de um mesmo governo. Isso era um grande problema, uma vez que a imensa maioria dos recursos orçamentários destinados aos projetos era executada pelas prefeituras. No que tange à participação da sociedade civil, há também casos de rotatividade dos membros e irregularidade na participação, explicados por falhas de comunicação entre a coordenação e os membros do colegiado e carências financeiras destes. Por outro lado, o "assembleísmo" - isto é, a ocorrência de muitas reuniões, frequentemente pouco produtivas e longas foi outro elemento que inibiu a participação dos representantes da sociedade civil. Ademais, a morosidade na execução dos projetos e a burocracia envolvida no seu encaminhamento eram fatores deletérios à participação, configurando-se num forte elemento de desmotivação.

O terceiro entrave refere-se a constrangimentos procedimentais que fragilizavam o processo decisório, como a falta ou o descumprimento de regras regimentais, a preeminência das deliberações por maioria, em detrimento da formação de consensos e a cristalização de grupos hegemônicos, pois, de fato, a supremacia de grupos de interesse bem articulados nas decisões do colegiado em relação a grupos minoritários menos poderosos fazia com que o "empoderamento" da sociedade civil fosse seletivo e, o que é pior, um fator de marginalização dos grupos com menor "capital social”, que tendiam a se afastar da arena deliberativa.

O quarto entrave tem a ver com fragilidades da ação coletiva, consubstanciadas pelo hiato entre as ideias planejadas e debatidas no colegiado e o processo de as colocar em prática, bem como a preeminência dos meios sobre os fins, isto é, do debate sobre os encaminhamentos, das ideias sobre a prática e da luta política sobre a mobilização produtiva. Ou seja, havia uma carência de competências

\footnotetext{
${ }^{13} \mathrm{O}$ inquérito aqui relatado foi realizado antes da implantação dos Núcleos de Extensão em Desenvolvimento Territorial (NEDETs), constituídos em universidades públicas no âmbito da Chamada Pública CNPq/MDA/SDT/SPM-PR nº 011/2014, os quais viriam a mitigar muitos desses problemas (Cf. Caniello e Teixeira, 2017; Teixeira e Caniello, 2018).
}

Revista Raízes, Campina Grande, v. 39, n. 2, jul./dez. 2019. 
organizacionais que comprometia a boa condução do processo e a criação de um ambiente favorável aos compromissos e arranjos consolidados.

O quinto entrave era a ausência de ações permanentes de avaliação e monitoramento de projetos e das próprias práticas nos colegiados, o que obstaculizava o desencadeamento de ajustes e aprimoramentos, extremamente importantes em processos inovadores e experimentais, como é a governança territorial.

O sexto entrave era a grande diversidade de situações, seja entre os colegiados, como evidenciam os escores do IGS e de suas dimensões, seja mesmo no interior dos territórios, o que informa laços de proximidade e relações de contraste entre subgrupos, gerando alinhamentos políticos e conflitos, como demonstrado alhures (Caniello; Piraux; Bastos, 2013b e 2014).

O sétimo entrave tem a ver com o quadro normativo e o formato institucional dos colegiados, que demonstravam grandes limitações (Piraux; Bonnal, 2011), fazendo com que sua pretendida autonomia se encontrasse obnubilada pela falta de um estatuto jurídico próprio para ele, pois, de fato, o "território rural" era um "não-lugar" no pacto federativo brasileiro. A falta desse estatuto limitava a capacidade de ação do colegiado, pois, sem reconhecimento jurídico, ele carecia de uma estrutura organizacional específica e dependia dos Entes federados ou de ONGs para o encaminhamento de seus projetos, fato que era agravado pelo absenteísmo e, mesmo, pelo boicote dos prefeitos. Enfim, os colegiados eram fóruns deliberativos constituídos por camponeses, mas eles dependiam de mediadores para executar suas deliberações e, assim, esses dispositivos de governança viam-se envolvidos por estruturas políticopartidárias, e técnicas e as burocracias a elas associadas, as quais drenavam recursos e submetiam os camponeses às suas agendas, dificultando o seu protagonismo no "ciclo de gestão social".

\section{CONSIDERAÇÕES FINAIS: PERSPECTIVAS PARA A GOVERNANÇA TERRITORIAL NO BRASIL}

Os impactos positivos do PRONAT no meio rural brasileiro, ressaltados pelos atores sociais entrevistados na pesquisa aqui analisada, no inquérito sobre o Índice de Condições de Vida (ICV) nos Territórios da Cidadania (Caniello, 2016) e evidenciados nos mais de 8 mil projetos implementados em seu âmbito, revelam o grande potencial da governança territorial para o desenvolvimento rural no Brasil. Entretanto o IGS apresentou um desempenho médio, o que pode ser interpretado, vis-à-vis a série de entraves que apresentamos na seção anterior, como uma evidência cabal de que os colegiados territoriais eram arranjos institucionais frágeis.

Assim, conclui-se que o enfoque territorial é uma estratégia de desenvolvimento rural viável - e, mesmo, desejável - para o país, mas a implementação de uma governança territorial eficaz deve levar 
em consideração três rotas possíveis. A primeira, mantendo-se as estruturas deliberativas como os colegiados instituídos pelo PRONAT, seria a implementação de duas medidas práticas: a associação deles a consórcios intermunicipais territoriais e o aperfeiçoamento das assessorias, num modelo misto em que pudessem atuar as ONGs e os Núcleos de Extensão em Desenvolvimento Territorial (NEDETs) vinculados às universidades públicas, os quais demonstraram um relativo sucesso no enfrentamento dos entraves apontados ${ }^{14}$.

Uma segunda rota seria o estabelecimento de um novo estatuto jurídico para a estrutura de governança territorial, o que também enfrenta um sério obstáculo: na atual conjuntura de regressão conservadora do Parlamento brasileiro é muito improvável que seja possível avançar em qualquer iniciativa progressista quanto à rediscussão do pacto federativo. Ademais, atualmente não há qualquer formulação acadêmica ou jurídica que aponte como poderia ser esse estatuto, sequer em suas linhas gerais. Seja como for, essa discussão tem que ser enfrentada caso a estratégia territorial seja retomada.

Enfim, chega-se à terceira rota: a construção da autonomia da governança territorial, o que aponta para três desafios que envolvem os atores, organizações e instituições presentes na dinâmica territorial. O primeiro é fomentar processos de formação visando desenvolver a aprendizagem organizacional, que poderiam ser conduzidos pelas universidades públicas, em parceria com as organizações atuantes nos territórios. Ora, a pesquisa aqui relatada indica que se deve dar uma maior atenção à qualificação prática dos membros do colegiado, municiando-os tecnicamente para uma postura mais proativa no que tange à sua ação efetiva no processo de desenvolvimento territorial. De fato, foi demonstrado neste trabalho que os melhores escores do IGS referem-se aos impactos positivos dos colegiados territoriais em relação à mudança de exercício do poder, à aprendizagem individual e, sobretudo, à consolidação dos laços sociais, o que se revela como a fonte potencial de um novo capital social. Contudo, a ativação desse capital social depende de uma aprendizagem organizacional que propicie a institucionalização progressiva dos arranjos de governança, única forma de os processos individuais evoluírem para processos coletivos, que são a base fundamental da governança territorial (Piraux et al, 2010). Nesse sentido, a construção de objetivos comuns e regras coletivas é um requisito fundamental para a emergência de uma nova cultura organizacional, o que significa, concretamente, adquirir novas competências, dentre as quais: aprender a problematizar, a desconstruir evidências, a dialogar, a definir responsabilidades, a lidar com conflitos, a avaliar ações. A aprendizagem organizacional permitiria, também, a construção de uma proposta local, constituindo a base de um projeto para o território.

O segundo desafio é a construção de um sistema de "inteligência territorial” (Piraux, 2015),

\footnotetext{
${ }^{14}$ Ver nota anterior.
} 
valendo-se das Tecnologias de Informação e Comunicação, de maneira que os processos e produtos do ciclo de gestão social, bem como os instrumentos e resultados de sua avaliação estejam permanentemente disponíveis aos atores envolvidos, criando-se um ambiente aberto para a inovação e o aperfeiçoamento das práticas.

Finalmente, o terceiro desafio seria a criação de um Fundo de Financiamento do Desenvolvimento Territorial, formado por recursos públicos e recursos captados em organismos de cooperação internacional, os quais, administrados pelo próprio colegiado em sua nova feição institucional, financiariam três elementos fundamentais para uma eventual "nova geração" da política territorial: um escritório administrativo que congregasse as capacidades organizativas do dispositivo de governança, uma Agência de Desenvolvimento Territorial que mobilizasse capacidades técnicas para o planejamento, elaboração, execução, monitoramento e avaliação de projetos, e o próprio custeio da participação dos membros, principalmente despesas de deslocamento e alimentação.

Para que tudo isso seja possível, é necessário, antes de mais nada, empoderar o capital social desenvolvido nos colegiados territoriais e remobilizá-lo. Na atual conjuntura da sociedade brasileira em que um governo central autoritário e antidemocrático patrocina forte regressão conservadora, desmonta as políticas públicas redistributivas e inovadoras, inclusive as territoriais, desarticula os meios de organização coletiva dos trabalhadores e impõe um neoliberalismo selvagem nas relações econômicas - o único caminho é o da disputa eleitoral. Somente as lideranças orgânicas que emergiram do ciclo de gestão social, legitimadas pelo voto popular, terão condições de mobilizar seus pares a lutar pela retomada da governança territorial no Brasil e, aliando-se às forças progressistas, retomar o curso da democracia participativa no país.

\section{REFERÊNCIAS}

ABRAMOVAY, Ricardo. Conselhos além dos limites, Estudos Avançados, vol. 15, nº 43, pp. 121-140, 2001.

ADIB, Alberto Renault. Plano Territorial de Desenvolvimento Rural Sustentável: guia para planejamento. Brasília, IICA Brasil, 2005.

BOBBIO, Norberto. O futuro da democracia: uma defesa das regras do jogo. Rio de Janeiro: Paz e Terra, 2000.

BONNAL, Philippe; KATO, Katarina. Análise comparativa de políticas públicas de desenvolvimento territorial. Relatório de Pesquisa. Rio de Janeiro: OPPA/CPDA/ UFRRJ; Brasília: IICA, 2010.

BRASIL. Censo Agropecuário 2006. Brasília, Instituto Brasileiro de Geografia e Estatística (IBGE), $2009 b$.

BRASIL. Censo Demográfico Brasileiro 2010. Brasília, IBGE, 2011.BRASIL. Ministério do 
Desenvolvimento Agrário (MDA). Orientação para constituição e funcionamento dos colegiados territoriais. Brasília, MDA/Departamento de Gestão Territorial, 2009.

BRASIL. Manual Operacional do PROINF 2015. Ação Orçamentária de Apoio a Infraestrutura em Territórios Rurais. Brasília: Ministério do Desenvolvimento Agrário/Secretaria de Desenvolvimento Territorial/Departamento de Inclusão Produtiva, 2015. Disponível em: http://www.mda.gov.br/sitemda/sites/sitemda/files/user_arquivos_383/Manual\%20Proinf\%202015_0.p df. Acesso em: 13 jun. 2016.

BUTTO, Andrea; BEMERGUY, Ester. A Cidadania nos Territórios: o olhar da Coordenação Executiva do Programa Territórios da Cidadania sobre o estado e as mudanças na agenda de desenvolvimento nacional. In: CAVALCANTI, J.S.B.; WANDERLEY, M.N.B.; NIEDERLE, P.A (Org.). Participação, Território e Cidadania: um olhar sobre a política de desenvolvimento territorial no Brasil. Recife: UFPE, 2014.

CAILLOSSE, J. Questions sur l'identité juridique de la 'gouvernance'. In: PASQUIER, R., SIMOULIN, V. ; WEINSTEIN, J. (dir.), La gouvernance territoriale. Pratiques, discours et théories, Paris, L.G.D.J., 2007, p. 35-64.

CANIELLO, M. Identidade e Qualidade de Vida nos Territórios da Cidadania na 'Década Inclusiva' Brasileira. Sociologias, Porto Alegre, Ano 18, n 43, set/dez, 2016, p. 300-334.

CANIELLO, M.; PIRAUX, M.; BASTOS, V. Capital social e desempenho institucional no Colegiado Territorial da Borborema, Paraíba. Revista Raízes, v. 32, n. 2, jul-dez, Campina Grande, 2012, p. 11-31.

CANIELLO, M.; PIRAUX, M.; BASTOS, V. Identidade e Participação Social na gestão do Programa Territórios da Cidadania: um estudo comparativo. Estudos Sociedade e Agricultura, v. 21, n. 1, Rio de Janeiro, 2013, p. 84-107.

CANIELLO, M.; PIRAUX, M.; BASTOS, V. Ideias e práticas na gestão social do Território da Cidadania da Borborema, Paraíba. Sustentabilidade em Debate, v. 4, n. 2, jul/dez, Brasília, 2013b, p. 1940.

CANIELLO, M.; PIRAUX, M.; BASTOS, V. Identidade e diversidade no Território da Cidadania da Borborema. Revista Raízes, v. 34, n. 1, jan/jun, Campina Grande, 2014, p. 24-48.

CANIELlO, M.; PIRAUX, M.; RAMBO, A. As Políticas Públicas Territoriais e o Desenvolvimento Rural Sustentável no Brasil Contemporâneo: Síntese do GT 9. In: ENCONTRO DA REDE DE ESTUDOS RURAIS, 6, 2012, Belém, UFPA. Anais do $6^{\circ}$ Encontro da Rede de Estudos Rurais.

CANIELLO, M.; TEIXEIRA, O. Os Núcleos de extensão universitária em desenvolvimento territorial e a governança participativa nos Territórios Rurais brasileiros: origem, processo, dissolução e perspectivas. In: FONTELES, J. O. (Org.). Território e territorialidade: democratizando saberes e boas práticas em políticas públicas. Sobral: Edições UVA; Sertão Cult, 2017, p. 17-34.

COREZOLA, Fernanda; OLIVEIRA, Carlos Douglas; ALMEIDA, Maria Graça. Desafios da governança territorial nos Territórios incorporados ao programa territórios da Cidadania. In: PIRAUX, Marc; CANIELO, Márcio (Org.). Dossiê território, sustentabilidade e ação pública, Revista Raízes, v. 28, n. 1 e 2; v. 29, n. 1, Campina Grande, UFCG, 2010, p. 87-96.

DAGNINO, E.; OLVERA, J. A.; PANFICHI, A. (Org.). A disputa pela construção democrática na América latina. Rio de Janeiro: Paz e Terra; Campinas-SP: Unicamp, 2006.

DALLABRIDA, V. R. (2015), Governança territorial: do debate teórico à avaliação da sua prática. Análise Social, 215, $1\left(2^{\circ}\right)$, pp. 304-328.

DELGADO, Nelson Giordano; LEITE, Sérgio Pereira. O Pronat e o PTC: possibilidades, limites e 
desafios das políticas territoriais para o desenvolvimento rural. In: GRISA, Catia; SCHNEIDER, Sérgio (Org.): Políticas públicas de desenvolvimento rural no Brasil. Porto Alegre: UFRGS, 2015.

DELGADO, Nelson Giordano; LEITE, Sérgio Pereira; BONNAL, Philippe. Desenvolvimento territorial: articulação de políticas públicas e atores locais. Rio de Janeiro, OPPA/CPDA/UFRRJ, 2007.

DOIMO, A. M. A vez e a voz do popular: movimentos sociais e participação política no Brasil pós-70. Rio de Janeiro, Relume-Dumará/ANPOCS, 1995.

GOHN, Maria da Glória. Conselhos gestores e participação sociopolítica. São Paulo: Cortez, 2001.

GRISA, C.; SCHNEIDER, S. Três gerações de políticas públicas para a agricultura familiar e formas de interação entre sociedade e Estado no Brasil. In: GRISA, C.; SCHNEIDER, S. (Org.) Políticas públicas de desenvolvimento rural no Brasil. Porto Alegre: UFRGS, 2015.

JARA, Carlos Júlio. A sustentabilidade do desenvolvimento local. Brasília, IICA; Recife, Secretaria de Planejamento do Estado de Pernambuco, 1998.

MALUF, Renato. Programas de desenvolvimento rural sustentável e a agricultura familiar no Brasil: enfoques, atores e escalas". In: PIRAUX, M.; CANIELLO M. (Org.). Dossiê território, sustentabilidade e ação pública. Revista Raízes, v. 28, n. 1 e 2; v. 29, n. 1, Campina Grande, UFCG, 2010, p. 19-26.

OLIVEIRA, Carlos Douglas de Sousa; VALENCIA, Mireya Eugenia Valencia. Gestão social no âmbito do Programa Desenvolvimento Sustentável de Territórios Rurais. In: ENCONTRO DA REDE DE ESTUDOS RURAIS, 5, 2012, Belém. Anais do $5^{\circ}$ Encontro da Rede de Estudos Rurais.

OLIVEIRA, José Humberto. Programa 'Territórios da Cidadania': uma estratégia de desenvolvimento territorial e garantia de direitos sociais voltados para as regiões de maior fragilidade socioeconômica. In: CONGRESO INTERNACIONAL DEL CLAD SOBRE LA REFORMA DEL ESTADO Y DE LA ADMINISTRACIÓN PÚBLICA, 13, 2008, Buenos Aires, Argentina. Anais do XIII Congreso Internacional del CLAD sobre la Reforma del Estado y de la Administración Pública.

PASQUIER, R.; SIMOULIN, V.; WEINSTEIN, J. (Org.). La gouvernance territoriale. Pratiques, discours et théories. Paris, L.G.D.J., 2007, p. 235.

PIRAUX, M. Avaliar as capacidades institucionais e o desempenho dos dispositivos de governança territorial. O caso dos Territórios da Cidadania no Brasil. In: CONGRESSO ALASRU, 9, 2014, México. Anais do IX Congresso ALASRU.

PIRAUX, M. Información y procesos de acompañamiento para la evaluación de la Gobernanza territorial: el caso de los Territorios de Ciudadanía nel brasil. Enseñanzas para México. In: Red CONACYT (ed). Territorio y gestión del desarrollo. Epistemologías y experiencias, Gestión Territorial del Desarrollo Rural Sustentable. México, 2015.

PIRAUX M.; BONNAL P. Ações públicas territoriais e inovações sociais e institucionais. O caso do território da Borborema e da Articulação do Semiárido. Estudos sociedade e agricultura, v. 19, n. 1, 2011, p. 62-87.

PIRAUX, M.; AZEVEDO, G. S.; TONNEAU, J.P. Os mediadores, os políticos e a sociedade civil: a realidade e os limites da governança territorial. Revista Raizes. Revista de ciências sociais e econômicas, v. 29, n. 1-2, Campinha Grande, UFCG, 2010, p. 97-108.

PIRAUX, M.; CANIELLO, M. Avanços, dilemas e perspectivas da governança territorial no Brasil: reflexões sobre o Programa de Desenvolvimento Sustentável de Territórios Rurais (PRONAT). In: MIRANDA, César Adrián Ramírez; MORENO, María del Carmen Hernández; TAPIA, Francisco Herrera; SÁNCHEZ, Alfonso Pérez (Org.). Gestión territorial para el desarrollo rural: construyendo un paradigma. México - DF: Juan Pablos Editor, 2016, p. 397-425. 
PIRAUX, M.; TONNEAU, J.P.; SABOURIN, E.; CHIA, E.; CANIELlO, M.; POLGUE, E.; MASSARDIEU, G. The challenges of territorial governance: the example of rural Brazil. In: Living territories to transform the world. Paris: Quae, 2017, p. 181-184.

REY-VALETTE, H. ; MATHÉ, S. L'évaluation de la gouvernance territoriale. Enjeux et propositions méthodologiques. Revue d'Économie Régionale \& Urbaine, n. 5, décembre, 2012, p. 783-804.

SANTOS, Boaventura de S.; AVRITZER, Leonardo. Introdução: para ampliar o cânone democrático. In: SANTOS, Boaventura de S. (Org.). Democratizar a democracia: os caminhos da democracia participativa. Rio de Janeiro: Civilização Brasileira, 2002.

SILVA, Enid Rocha Andrade da. Participação social e as Conferências Nacionais de Políticas Públicas: reflexões sobre os avanços e desafios no período de 2003-2006. Brasília: IPEA, 2009 (Texto para Discussão $n^{0} 1378$ ).

SIMOULIN, V. La gouvernance: dynamiques discursives, stratégiques et organisationnelles. In: PASQUIER, R.; SIMOULIN, V.; WEINSTEIN, J. (dir.). La gouvernance territoriale. Pratiques, discours et théories. Paris, L.G.D.J., 2007, p. 15-32.

TEIXEIRA, O.; CANIELLO, M. Fragilidades, limites e desafios do financiamento da infraestrutura para o desenvolvimento territorial brasileiro. In: Bienal del Coloquio de Transformaciones Territoriales: repensando políticas y estratégias, 11, 2016, Ciudad del Salto, Uruguay: CENUR Litoral Norte, p. 314324. Anales XI Bienal del Coloquio de Transformaciones Territoriales: repensando políticas y estratégias.

TEIXEIRA, O.; CANIELLO, M. Extensão universitária, governança participativa e desenvolvimento territorial: a experiência dos NEDETs. In: NEVES, F.A.F. Extensão no quotidiano da Universidade, um exercício de interpretação ou de intervenção?. Belém: Pró-Reitoria de Extensão/UFPA, 2018.

VALENCIA, M. et. al. Doze anos do Programa Desenvolvimento Sustentável de Territórios Rurais do Ministério de Desenvolvimento Agrário do Brasil: como vamos?. Santiago: Centro Latinoamericano para el Desarrollo Rural (RIMISP), 2015, inédito. 